\title{
Conservation physiology can inform threat assessment and recovery planning processes for threatened species
}

\author{
Kim Birnie-Gauvin ${ }^{1,2, *}$, Sarah Walton ${ }^{1}$, Caleigh A. Delle Palme ${ }^{1}$, \\ Beckie A. Manouchehri ${ }^{1,3}$, Simon Venne ${ }^{4}$, Robert J. Lennox ${ }^{1}$, \\ Jacqueline M. Chapman ${ }^{1}$, Joseph R. Bennett ${ }^{3}$, Steven J. Cooke ${ }^{1}$
}

\author{
${ }^{1}$ Fish Ecology and Conservation Physiology Laboratory, Department of Biology and Institute of Environmental Science, \\ Carleton University, 1125 Colonel By Drive, Ottawa, ON K1S 5B6, Canada \\ ${ }^{2}$ DTU Aqua, National Institute of Aquatic Resources, Section for Freshwater Fisheries Ecology, \\ Technical University of Denmark, Vejlsøvej 39, 8600 Silkeborg, Denmark \\ ${ }^{3}$ Department of Biology and Institute of Environmental Science, Carleton University, 1125 Colonel By Drive, Ottawa, \\ ON K1S 5B6, Canada \\ ${ }^{4}$ Department of Biology, University of Ottawa, 30 Marie-Curie, Ottawa, ON K1N 6N5, Canada
}

\begin{abstract}
Conservation physiology has emerged as a discipline with many success stories. Yet, it is unclear how it is currently integrated into the activities of the IUCN and other bodies which undertake international, national, or regional species threat assessments and work with partners to develop recovery plans. Here we argue that conservation physiology has much to offer for the threat assessment process and we outline the ways in which this can be operationalized. For instance, conservation physiology is effective in revealing causal relationships and mechanisms that explain observed patterns, such as population declines. Identifying the causes of population declines is a necessary precursor to the design of actions to reverse or mitigate such threats. Conservation physiology can also identify complex interactions and support modeling activities that consider emerging threats. When a population or species is deemed threatened and recovery plans are needed, physiology can be used to predict how organisms will respond to the conservation intervention and future threats. For example, if a recovery plan was focused on translocation, understanding how to safely translocate organisms would be necessary, as would ensuring that the recipient habitat provides the necessary environmental characteristics to meet the fundamental physiological needs/tolerances of that organism. Our hope is that this paper will clarify ways in which physiological data can make an important contribution to the conservation activities of bodies like the IUCN that are engaged in threat assessment and recovery of endangered organisms. Although we focus on activities at the international scale, these same concepts are relevant and applicable to national and regional bodies.
\end{abstract}

KEY WORDS: Endangered species · Physiology · IUCN · Threat assessments · Recovery planning · Conservation

\section{INTRODUCTION}

In its simplest form, conservation physiology is defined as 'the study of physiological responses of organisms to human alteration of the environment that might cause or contribute to population declines'

${ }^{*}$ Corresponding author: kbir@aqua.dtu.dk
(Wikelski \& Cooke 2006, p. 38). It involves the application of physiological concepts, knowledge, and tools to identify and solve conservation problems (Cooke et al. 2013). A recently developed conceptual framework for conservation physiology clearly articulates the pathways in which physiology can inform

(C) The authors 2017. Open Access under Creative Commons by Attribution Licence. Use, distribution and reproduction are unrestricted. Authors and original publication must be credited. 
conservation policy and practice (Coristine et al. 2014). While a range of other endpoints may be used (e.g. diversity, reproductive output, size structure, etc.), measurements of population declines are of crucial importance for threat assessments conducted by entities such as the International Union for Conservation of Nature and Natural Resources (IUCN) as part of the Red List process (Mace et al. 2008). Scientifically based determination of the threat status of a given species or population is a key step in order to allocate necessary resources and apply appropriate conservation interventions, ranging from policy to hands-on in situ and ex situ conservation actions (Rodrigues et al. 2006, Vié et al. 2009). To prevent future declines, or reverse current population declines, we must first understand the underlying causes of such declines (Boersma et al. 2001). Physiology can provide valuable causal information by helping identify how organisms acquire, metabolize, and allocate resources. Furthermore, physiology can help us understand how organisms maintain homeostasis and adapt to changing environments. Thus, physiology can be incorporated into a mechanistic framework to determine how natural and anthropogenic stressors may be affecting organisms.

Here, we aim to describe how physiology may be applied to various threat assessment components and recovery planning processes defined by the IUCN. We present specific case studies to illustrate the use of conservation physiology in real world examples, as well as to further demonstrate where physiology could assist threat assessments and recovery planning. The case studies were selected to yield taxonomic and geographic diversity. We finish by presenting a framework suggesting how conservation physiology may assist in assigning status, along with the important limitations to consider along the process. Although we focused on the IUCN, our proposed approach is equally relevant to other international, national and regional threat assessment processes, such as the Climate Change Vulnerability Index developed by NatureServe (www.natureserve. org/conservation-tools/climate-change-vulnerabilityindex).

\section{APPLYING PHYSIOLOGY TO THREAT ASSESSMENTS AND RECOVERY PLANNING}

Global biodiversity loss due to human activities is occurring at a rate comparable to previous global mass extinctions (Barnosky et al. 2011). To track species vulnerability, organizations such as the
IUCN rely heavily on population size and distribution information, i.e. geographical distribution and the extent of fragmentation among populations (Hoffmann et al. 2008). Criteria used by the IUCN to determine the threat status of species as Vulnerable, Endangered or Critically Endangered are as follows: (A) population size reduction, (B) geographic range (extent and area of occupancy), (C) small population size and decline, (D) very small or restricted population, and (E) quantitative analysis for extinction risk (IUCN 2012; Fig. 1). The threat levels identified above are distinguished using data that suggest levels of decline reversibility and suspension, or the elimination of mechanisms responsible for triggering the decline.

This paper illustrates the various ways in which some common physiological tools can be implemented into the IUCN threat assessments, and thus help in assigning status (Fig. 1). We acknowledge that there are more ways to apply physiological tools than we describe, and that this list of physiological tools and their applications is dynamic and subject to change as physiological techniques evolve. Furthermore, we acknowledge that much of the physiological data will be most useful when combined with other information (e.g. environmental elements, population estimates). Nonetheless, physiology can provide data on the underlying issues that drive species decline, or help predict responses to future threats, and as such may be useful in threat assessments and recovery planning.

Physiological tools applicable to IUCN criteria include comparative, environmental, ecological, neurosensory and cardiorespiratory physiology, environmental toxicology, immunology, chemical communication, bioenergetics and nutrition, locomotor performance, reproduction, and genomics (Fig. 1). Such tools may be used to 'infer, project, and/or suspect' (IUCN 2012) a species' threat level by scaling up individual responses to population response, with the tacit assumption that individual physiological responses are representative of the population. 'Estimated' threat may only be applied to very small or restricted populations (Criterion D, Fig. 1) as all individuals must be accounted for (IUCN 2012, Fig. 1); 'observed' data are outside the capable scope of conservation physiology.

The assessment process also considers factors such as species habitat, relevant threats and stressors to direct conservation actions and research needs (see www.iucnredlist.org/technical-documents/classification-schemes). Physiology may be helpful for acquiring this information. However, for a species to be 
IUCN Red Listing Criteria

Type of data

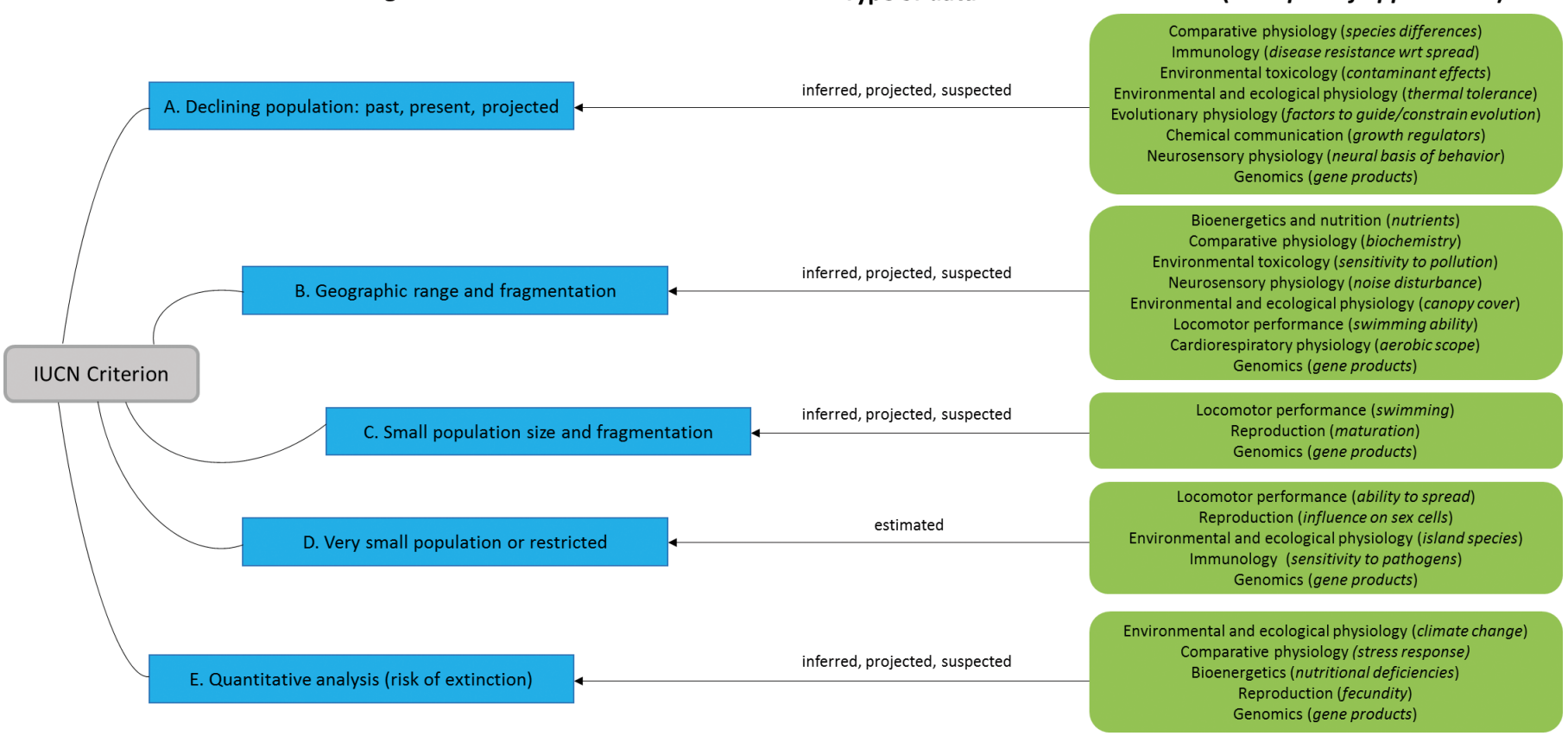

Fig. 1. Use of physiological tools in IUCN threat assessment. Proposed framework on how to use physiological tools (green, with examples in italics) to inform the various IUCN criteria (blue)

assigned a higher threat level (i.e. Critically Endangered), population declines must already be observed throughout the species' global range. It is worth acknowledging that there are inherent challenges associated with accurate population assessments of wild organisms, especially those that are rare, such that there can be significant uncertainty with threat assessments (Colyvan et al. 1999).

While recording overall population declines provides critical information for conservation, incorporating the physiological mechanisms driving changes in populations would provide a mechanistic understanding of how threats impact an organism's ability to obtain energy, survive, and reproduce. This information can be used to forecast how a plant or animal may respond to prolonged exposure to similar or higher magnitude anthropogenic stressors (Fig. 1). In this way, physiology can improve the scientific basis for assigning threat status using most criteria, and likely increase the probability of developing successful recovery plans. In addition, characterizing physiological responses to anthropogenic stressors could provide managers with early warning signs that population declines may occur (Criterion A, Fig. 1). Better understanding of environmental and ecological physiology may also strengthen predictions of population-level responses to anthropogenic stressors (Criteria A, B \& E, Fig. 1). For example, Catenazzi et al. (2014) demonstrated that thermal stress increases susceptibility to pathogen-induced mortality in South American amphibians, highlighting potential for population crashes in climate warming scenarios. In recovery programs, knowledge of reproductive physiology and consequent habitat requirements can improve conservation strategies, including captive breeding programs (Criteria C, D \& E, Fig. 1; O'Brien \& Robeck 2010).

\section{REAL WORLD SCENARIOS: APPLYING PHYSIOLOGY FOR IUCN THREAT ASSESSMENTS}

\section{Endemic species of Hawaii and Madagascar}

Geographic isolation, habitat heterogeneity, and climatic variation of islands produce a disproportionate fraction of endemic taxa which are susceptible to anthropogenic threats (Roberson 2006, Whittaker \& Fernández-Palacios 2007). Use of physiological tools may elucidate adaptive potential and ecological susceptibility of endemic island taxa to climate change, habitat reduction and invasive species using all IUCN criteria. Use of physiological tools may also increase our capacity to assess the status of island taxa with restricted population sizes (Criterion D, Fig. 1). 
The IUCN emphasized the need for data on endemic amphibian, reptilian and plant taxa (Callmander et al. 2005, Giam et al. 2010) in biodiversity hotspots Hawaii and Madagascar. Recent work has focused on status assessments for expansion of protected areas to maximize conservation of endemic richness within contrasting habitats in both areas (Callmander et al. 2007, Andreone et al. 2008, Miller \& Porter Morgan 2011, Jenkins et al. 2014, Rakotoarinivo et al. 2014). Physiological research is helping to address eco-physiological performance and functions not supported by protected areas that influence population dynamics of vulnerable plant, amphibian and reptilian species (Vallan 2002, Andreone et al. 2008, Blaustein et al. 2012). For example, to understand colonization and distribution mechanisms in order to model and manage impacts of invasions, in situ photosynthetic capacity of introduced plants species in Hawaii's endangered dry forest were compared; species-specific physiological and morphological traits were strongly correlated to plant biomass, but photosynthetic physiology was functionally equivalent (Cordell et al. 2002).

Another important factor that must be considered in order to conserve endemic species of geographically isolated regions is species mutualism (Colwell et al. 2012). For example, seed-dispersal mutualisms between endemic plants and reptile species provide an important approach to investigate cause-andeffect relationships between these 2 taxa, given that the nutritional needs and digestive processes of the reptiles are fundamental to the plants (Ruxton \& Schaefer 2012). Endemic lizards and other tropical ectotherms, for instance, are important seed dispersers in island habitats (Hansen \& Muller 2009). Understanding such mutualisms may elucidate population dynamics useful to Red List assessments.

\section{Oxidative stress as a population health indicator in Antarctic penguins}

Antarctica is home to the gentoo penguin Pygoscelis papua and the Adélie penguin $P$. adeliae and is an area showing great environmental vulnerability to climate change, especially due to increasing water temperature, decreasing ice cover and diminished krill populations (Bennett et al. 2015). Both penguin species are listed as Near Threatened by the IUCN (Beaulieu et al. 2015, D'Amico et al. 2016, IUCN 2016), though they demonstrate contrasting demographic trends within different regions of Antarctica (Beaulieu et al. 2013).
Recently, the use of oxidative stress markers to estimate population health of animal populations has shown great promise for conservation (Beaulieu et al. 2013, Beaulieu \& Constantini 2014). Populations with poor antioxidant defenses may decline under environmental conditions where pro-oxidants are favored (Noguera et al. 2012, Beaulieu et al. 2013). Beaulieu et al. (2013) found that penguins in increasing populations had higher antioxidant defenses than those in decreasing populations. Decreased antioxidant capacity has several implications, most prominently, reductions in fitness, fertility and survival (Bize et al. 2008, Beaulieu et al. 2013). Monitoring oxidative stress in Antarctic penguins may provide early warning indicators of the impacts of climate change or other stresses, and subsequently project or infer population declines (Criterion A, Fig. 1).

\section{Reproduction, genomics and nutrition: conservation of kiwis in New Zealand}

Since the arrival of Europeans in New Zealand, the island's 5 endemic species of kiwi Apteryx spp. have faced a rapid decrease in population size, and all were initially labeled as Endangered or Critically Endangered by the IUCN (McLennan 1988, Holzapfel et al. 2008). Deforestation and the introduction of predatory mammals (specifically stoats and dogs) have been the primary threats to kiwi survival (McLennan 1988, McLennan et al. 1996, Basse et al. 1999). Research on kiwi physiology has had great success in informing IUCN threat assessment (Criteria C, D \& E, Fig. 1) and implementing recovery plans. One of New Zealand's major conservation efforts, Operation Nest Egg (ONE), has depended primarily on physiological data to inform its research protocol (Colbourne et al. 2005, Holzapfel et al. 2008). Kiwi reproduction is unique amongst birds and characterized by large egg sizes (taking up to 15 to $20 \%$ of the female's body cavity), rapid egg development (30 d from conception to laying), small clutches (generally a single egg), long incubation periods ( 74 to $84 \mathrm{~d}$ ) shared by both male and female, and lack of parental-provided chick feeding (an external yolk sac provides nutrition for the first $10 \mathrm{~d}$ after hatching) (Colbourne 2002, Robertson et al. 2011). Physiological data on kiwi reproduction led to development of the ONE protocol to boost the kiwi populations. The protocol begins with removal of eggs from nests (located via radio telemetry of adult pairs), which are then incubated, hatched and the young reared in a secure ex situ 
environment (McLennan 1988, Colbourne et al. 2005, Holzapfel et al. 2008). Young are released into a predator-free zone to learn effective foraging techniques prior to release into the wild as adults (Robertson et al. 2011). Genetics of the reared kiwis determine where they are released as adults to ensure genetic diversity and survival (Colbourne et al. 2005, Le Duc et al. 2015). This translocation program informed by physiological data has aided in the reclassification of 2 kiwi species to Vulnerable, and a third species to Near Threatened (IUCN 2016). Importantly, physiology was one of several tools (i.e. molecular genetics, behavioural assays) used in this process.

\section{Migratory fish, river modifications, and physiological tolerances}

Many migratory freshwater fish are in a state of global decline (IUCN 2016) and require immediate status assessments to inform conservation actions. Migratory fish exhibit complex life histories, often using both freshwater and marine environments throughout their life cycle (Bemis \& Kynard 1997). Complex life histories can exacerbate challenges associated with applying IUCN Red List Criteria A, $B$ and E (Fig. 1) (Liermann et al. 2012, Jacoby et al. 2014, 2015). Use of physiological tools may identify how hydrological impacts influence successful recruitment and address knowledge gaps related to specific life-stage survival, thus helping to infer or project rates of population decline (Jacoby et al. 2015). Physiological tools may further elucidate mechanisms that influence population level responses to natural (e.g. thermal increase) and artificial (e.g. hydroelectric dam) riverine modifications (Cooke 2008), providing data that may inform all assessment criteria. For example, Verhille et al. (2014) assessed the swimming capacity of larval sturgeon to reduce entrainment risk in water-diversion structures, a known factor in population decline. Whiterod (2013) used bioenergetics to develop a swimming-performance model that identified susceptibility of juvenile Murray cod Maccullochella peelii to hydroelectric operations in the Murray Darling basin, Australia (Kearney \& Kildea 2001). With elevated conservation concerns surrounding the status of endangered migratory freshwater fish (Jacoby et al. 2014), use of sensory, neurophysiological, eco-physiological and biotelemetry tools may expedite the acquisition of data to accurately determine threat levels.

\section{LIMITATIONS TO THE USE OF CONSERVATION PHYSIOLOGY IN THREAT ASSESSMENTS}

Although conservation physiology is broadly applicable to understanding conservation threats and developing solutions, there are some key limitations to integrating physiological knowledge and tools into IUCN threat assessments. Many candidate species at risk exist in small, isolated populations and must be studied in the wild, whereas many physiological tools are suited to laboratory or captive animal applications. Working with wild animals, particularly with sensitive species, means that the suite of physiological tools available for sampling may be limited to assays that are non-lethal and minimally invasive, excluding some relevant tests that require lethal sampling or invasive surgery (e.g. whole body cortisol, organ histology, muscle energetics). In some cases, it may be possible to use surrogate species for developing these concepts (Wenger 2008), although this approach should be used with caution. There are increasing examples of minimally invasive biopsies that can be taken from wild animals, and many physiological tools are being adapted for use in the field (e.g. point-of-care sampling devices; Stoot et al. 2014). However, measurements of physiological stress responses (e.g. primary stress response, heart rate, oxygen consumption) must consider the time-course of changes in the response, comparing baseline, peak, and return to resting values. Baseline responses are logistically difficult to generate because animals must be captured and handled to obtain samples, creating an inherent stress response bias (Pankhurst 2011). This may prove particularly difficult in the context of regional assessments in developing countries where such technical capacity may not exist.

Furthermore, to apply physiological data to a population, the number of individuals sampled must be sufficiently large to account for potential variation in factors such as age, sex, and size. Lastly, limitations may include temporal or financial factors. Physiological work can be time consuming and expensive, and when balanced against the need for an immediate listing decision based on current information (e.g. populations in severe decline), there may also be situations where physiological information is not justified before listing and/or action must begin.

\section{CONCLUSIONS AND OUTLOOK TO THE FUTURE}

Understanding physiological responses is essential to determine how a species may respond to stressors. 
In the wild, species are often exposed to more than a single stressor at a time (Boonstra 2013), and the extent of their combined or cumulative impacts can be elucidated using physiology, which provides information that one cannot necessarily observe through basic behavioral studies. In conservation, physiology is most relevant when making predictions of future responses to known threats. For example, an organism's physiology constrains the range of environments in which it can live (Seebacher \& Franklin 2012) and can help us understand how habitat loss or fragmentation may affect it. Physiological responses to known threats such as pollutants and climate change may also provide valuable data needed to make informed threat assessments. Physiology can supplement ecological and behavioral data for species where more research is needed, but approaches and techniques to obtain such data are limited (e.g. qualitative observations). As such, physiology is especially useful for recovery planning. Additionally, physiology can be integrated into models used to estimate probability of extinction (Criterion E, Fig. 1) and render this assessment more reliable, though assigning probability of extinction requires more data than physiology alone can provide. We acknowledge that physiological data cannot inform all criteria without making some assumptions, or combining the data with other available information (e.g. knowledge on the distribution of environmental variables which may be causative factors for physiological outcomes). However, new threats, or threats that are still poorly understood (e.g. climate change) may require the application of new techniques and approaches to informing IUCN threat assessments, which conservation physiology can provide. Combined with other techniques, the use of physiology can provide us with a powerful tool to assess threats and plan recovery strategies.

Acknowledgements. S.J.C. is supported by the Canada Research Chairs Program and the Natural Sciences and Engineering Research Council of Canada (NSERC). J.R.B. is supported by an NSERC Discovery Grant. We also thank 3 referees for providing thoughtful input on the paper.

\section{LITERATURE CITED}

Andreone F, Carpenter I, Cox N, du Preez L and others (2008) The challenge of conserving amphibian megadiversity in Madagascar. PLOS Biol 6:e118

Barnosky AD, Matzke N, Tomiya S, Wogan GO and others (2011) Has the Earth's sixth mass extinction already arrived? Nature 471:51-57

Basse B, McLennan JA, Wake GC (1999) Analysis of the impact of stoats, Mustela erminea, on northern brown kiwi, Apteryx mantelli, in New Zealand. Wildl Res 26: 227-237

“Beaulieu M, Thierry AM, González-Acuña D, Polito MJ (2013) Integrating oxidative ecology into conservation physiology. Conserv Physiol 1:cot004

Beaulieu M, Costantini D (2014) Biomarkers of oxidative status: missing tools in conservation physiology. Conserv Physiol 2:cou014

Beaulieu M, González-Acuña D, Thierry AM, Polito MJ (2015) Relationships between isotopic values and oxidative status: insights from populations of gentoo penguins. Oecologia 177:1211-1220

Bemis WE, Kynard B (1997) Sturgeon rivers: an introduction to acipenseriform biogeography and life history. Environ Biol Fishes 48:167-183

Bennett JR, Shaw JD, Terauds A, Smol JP and others (2015) Polar lessons learned: long-term management based on shared threats in Arctic and Antarctic environments. Front Ecol Environ 13:316-324

* Bize P, Devevey G, Monaghan P, Doligez B, Christe P (2008) Fecundity and survival in relation to resistance to oxidative stress in a free-living bird. Ecology 89: 2584-2593

Blaustein AR, Gervasi SS, Johnson PTJ, Hoverman JT, Beldon LK, Bradley PW, Xie GY (2012) Ecophysiology meets conservation: understanding the role of diseases in amphibian population declines. Philos Trans R Soc B 367: 1688-1707

Koersma PD, Kareiva P, Fagan WF, Clark JA, Hoekstra JM (2001) How good are endangered species recovery plans? BioScience 51:643-649

Boonstra R (2013) Reality as the leading cause of stress: rethinking the impact of chronic stress in nature. Funct Ecol 27:11-23

* Callmander MW, Schatz GE, Lowry PP (2005) IUCN Red List assessment and the Global Strategy for Plant Conservation: taxonomists must act now. Taxon 54: 1047-1050

* Callmander MW, Schatz GE, Lowry PP, Laivao MO and others (2007) Identification of priority areas for plant conservation in Madagascar using Red List criteria: rare and threatened Pandanaceae indicate sites in need of protection. Oryx 41:168-176

Catenazzi A, Lehr E, Vredenburg VT (2014) Thermal physiology, disease, and amphibian declines on the eastern slopes of the Andes. Conserv Biol 28:509-517

Colbourne R (2002) Incubation behaviors and egg physiology of kiwi (Apteryx spp.) in natural habitats. N Z J Ecol 26:129-138

Colbourne R, Bassett S, Billing T, McCormick H, McLennan JA, Nelson A, Robertson H (2005) The development of Operation Nest Egg as a tool in the conservation management of kiwi. Department of Conservation, Wellington

* Colwell RK, Dunn RR, Harris NC (2012) Coextinction and persistence of dependent species in a changing world. Annu Rev Ecol Evol Syst 43:183-203

* Colyvan M, Burgman MA, Todd CR, Akcakaya HR, Boek C (1999) The treatment of uncertainty and the structure of the IUCN threatened species categories. Biol Conserv 89:245-249

Cooke SJ (2008) Biotelemetry and biologging in endangered species research and animal conservation: relevant to regional, national and IUCN Red List threat assessments. Endang Species Res 4:165-185 
Cooke SJ, Sack L, Franklin CE, Farrell AP, Beardall J, Wikelski M, Chown SL (2013) What is conservation physiology? Perspectives on an increasingly integrated and essential science. Conserv Physiol 1:cot001

Cordell S, Cabin RJ, Hadway LJ (2002) Physiological ecology of native and alien dry forest shrubs in Hawaii. Biol Invasions 4:387-396

Coristine LE, Robillard CM, Kerr JT, O'Connor CM, Lapointe D, Cooke SJ (2014) A conceptual framework for the emerging discipline of conservation physiology. Conserv Physiol 2:cou033

* D'Amico VL, Marcelo B, Benzal J, Coria N, Vidal V, Diaz JI, Barbosa A (2016) Leukocyte counts in different populations of Antarctic pygoscelid penguins along the Antarctic Peninsula. Polar Biol 39:199-206

Giam X, Bradshaw CJA, Tan HTW, Sodhi NSS (2010) Future habitat loss and conservation of plant biodiversity. Biol Conserv 143:1594-1602

Hansen DM, Muller CB (2009) Invasive ants disrupt gecko pollination and seed dispersal of the endangered plant Roussea simplex in Mauritius. Biotropica 41:202-208

* Hoffmann M, Brooks TM, da Fonseca GAB, Gascon C and others (2008) Conservation planning and the IUCN Red List. Endang Species Res 6:113-125

Holzapfel S, Robertson HA, McLennan JA, Sporle W, Kevin Hackwell K, Impey M (2008) Kiwi (Apteryx spp.) recovery plan. Department of Conservation, Wellington

IUCN (2012) IUCN Red List categories and criteria: version 3.1, 2nd edn. IUCN, Gland

IUCN (2016) IUCN Red List: an overview of the IUCN Red List. IUCN, Gland. www.iucnredlist.org/about/overview

* Jacoby D, Casselman J, DeLucia M, Hammerson GA, Gollock M (2014) Anguilla rostrata. The IUCN Red List of Threatened Species 2014: e.T191108A72965914. http://dx.doi.org/10.2305/IUCN.UK.2014-3.RLTS.T191108A72965914.en

Jacoby DM, Casselman JM, Crook C, DeLucia MB and others (2015) Synergistic patterns of threat and the challenges facing global anguillid eel conservation. Glob Ecol Conserv 4:321-333

Jenkins RKB, Tognelli MF, Bowles P, Cox N and others (2014) Extinction risks and the conservation of Madagascar's reptiles. PLOS ONE 9:e100173

Kearney RE, Kildea MA (2001) The status of Murray cod in the Murray-Darling Basin. Department of the Environment and Heritage, Applied Ecology Research Group, University of Canberra

Ke Duc D, Renaud G, Krishnan A, Almén MS and others (2015) Kiwi genome provides insights into evolution of a nocturnal lifestyle. Genome Biol 16:147

Liermann CR, Nilsson C, Robertson J, Ng RY (2012) Implications of dam obstruction for global freshwater fish diversity. BioScience 62:539-548

Mace GM, Collar NJ, Gaston KJ, Hilton-Taylor C and others (2008) Quantification of extinction risk: IUCN's system for classifying threatened species. Conserv Biol 22: 1424-1442

McLennan JA (1988) Breeding of North Island brown kiwi, Apteryx australis mantelli, in Hawke's Bay, New Zealand. N Z J Ecol 11:89-97

McLennan JA, Potter MA, Robertson HA, Wake GC and others (1996) Role of predation in the decline of kiwi, Apteryx spp., in New Zealand. N Z J Ecol 20:27-35
Miller JS, Porter Morgan HA (2011) Assessing the effectiveness of Madagascar's changing protected system: a case study of threatened Borginales. Oryx 45: 201-209

Noguera JC, Kim SY, Velando A (2012) Pre-fledging oxidative damage predicts recruitment in a long-lived bird. Biol Lett 8:61-63

O'Brien JK, Robeck TR (2010) The value of ex situ cetacean populations in understanding reproductive physiology and developing assisted reproductive technology for ex situ and in situ species management and conservation efforts. Int J Comp Psychol 23:227-248

* Pankhurst NW (2011) The endocrinology of stress in fish: an environmental perspective. Gen Comp Endocrinol 170: 265-275

Rakotoarinivo M, Dransfield J, Bachman SP, Moat J, Baker WJ (2014) Comprehensive red list assessment reveals exceptionally high extinction risk to Madagascar palms. PLOS ONE 9:e103684

* Roberson MR (2006) Evolutionary biologists aim to protect Madagascar's plants and animals. American Institute of Biological Sciences. www.actionbioscience.org/evolution/ roberson.html\#primer

Kobertson HA, Colbourne RM, Graham PJ, Miller PJ, Pierce RJ (2011) Experimental management of brown kiwi Apteryx mantelli in central Northland, New Zealand. Bird Conserv Int 21:207-220

* Rodrigues AS, Pilgrim JD, Lamoreux JF, Hoffmann M, Brooks TM (2006) The value of the IUCN Red List for conservation. Trends Ecol Evol 21:71-76

* Ruxton GD, Schaefer HM (2012) The conservation physiology of seed dispersal. Philos Trans R Soc B 367 : 1708-1718

* Seebacher F, Franklin CE (2012) Determining environmental causes of biological effects: the need for a mechanistic physiological dimension in conservation biology. Philos Trans R Soc B 367:1607-1614

* Stoot LJ, Cairns NA, Cull F, Taylor JJ and others (2014) Use of portable blood physiology point-of-care devices for basic and applied research on vertebrates: a review. Conserv Physiol 2:cou011

*Vallan D (2002) Effects of anthropogenic environmental changes on amphibian diversity in the rain forests of Madagascar. J Trop Ecol 18:725-742

*Verhille CE, Poletto JB, Cocherell DE, DeCourten B, Baird S, Cech JJ Jr, Fangue NA (2014) Larval green and white sturgeon swimming performance in relation to waterdiversion flows. Conserv Physiol 2:cou031

Vié JC, Hilton-Taylor C, Pollock C, Ragle J, Smart J, Stuart SN, Tong R (2008) The IUCN Red List: a key conservation tool. In: Vié JC, Hilton-Taylor C, Stuart SN (eds) The 2008 review of the IUCN Red List of Threatened Species. IUCN, Gland, p 1-14

Wenger SJ (2008) Use of surrogates to predict the stressor response of imperiled species. Conserv Biol 22:1564-1571

*Whiterod NS (2013) The swimming capacity of juvenile Murray cod (Maccullochella peelii): an ambush predator endemic to the Murray-Darling Basin, Australia. Ecol Freshw Fish 22:117-126

Whittaker RB, Fernández-Palacios J (2007) Island biogeography, 2nd edn. Oxford University Press, Oxford

Wikelski M, Cooke SJ (2006) Conservation physiology. Trends Ecol Evol 21:38-46

Submitted: January 23, 2017; Accepted: April 7, 2017 Proofs received from author(s): June 1, 2017 